\title{
A survey of pituitary incidentaloma in Japan
}

\author{
Naoko Sanno, Ken'ichi Oyama, Shigeyuki Tahara, Akira Teramoto and Yuzuru Kato ${ }^{1}$ \\ Department of Neurosurgery, Nippon Medical School, 1-1-5 Sendagi Bunkyo-ku 113-8603, Tokyo and ${ }^{1}$ Department of Internal Medicine, \\ Shimane Medical University, 89-1 Sioji-cho Izumo 693-8501, Shimane, Japan
}

(Correspondence should be addressed to N Sanno, Department of Neurosurgery, Nippon Medical School, 1-7-1 Nagayama Tama, 206-8512 Tokyo, Japan; Email: sanno-n@nms.ac.jp)

\begin{abstract}
Objective: The development of computed tomography (CT) and magnetic resonance imaging (MRI) has resulted in the discovery of unsuspected endocrinologically silent pituitary masses (pituitary incidentalomas). The aim of this study was to perform a national survey on pituitary incidentalomas in order to establish an appropriate approach to them.

Design and methods: Five hundred and six patients with pituitary incidentalomas were obtained by questionnaire from March 1999 to May 2000 under the auspices of the Ministry of Health, Labor and Welfare in Japan. Two hundred and fifty-eight patients underwent surgery (surgical group), while 248 patients were followed up conservatively for a mean period of 26.9 months (range 6-173 months) (non-surgical group). Clinical and biochemical assessment, CT or MRI of the pituitary, and visual field testing by Goldman perimetry were assessed at baseline and 6 months and yearly thereafter.

Results: Thirty-three patients with pituitary incidentalomas (13.3\%) developed tumor enlargement during the mean follow-up period of 45.5 months. Of 115 estimated non-functioning adenomas, 23 tumors $(20.0 \%)$ increased during a mean follow-up period of 50.7 months (range 10-173 months), while 5 of 94 (5.3\%) estimated Rathke's cysts increased in size during follow-up. Pituitary apoplexy occurred in one of 248 patients $(0.4 \%)$.

Conclusions: Pituitary incidentalomas usually follow a benign course. We recommend transsphenoidal adenectomy for a solid mass attached to the optic chiasma estimated to be a pituitary adenoma by MRI. Other patients should be followed up by MRI every 6 months for the first 2 years, and then yearly.
\end{abstract}

European Journal of Endocrinology 149 123-127

\section{Introduction}

The development of computed tomography (CT) and magnetic resonance imaging (MRI) has resulted in the discovery of unsuspected endocrinologically silent masses in the pituitary (pituitary incidentalomas) (1-3). In autopsy series, the prevalence of pituitary incidentalomas is reported to be $3-27 \%$ (4-7). With the widespread use of CT and MRI, the incidental discovery of pituitary masses is increasing in frequency $(8-11)$. Studies of incidentalomas are limited to case series $(6-10)$. Because the natural history of this entity is not clearly known, clear guidelines on the management of pituitary incidentaloma have not been established. The aim of the present study was to determine the natural history of untreated pituitary incidentalomas. We studied 506 patients with incidentally discovered pituitary masses collected in 41 centers in Japan.

\section{Subjects and methods}

A multicenter, retrospective survey of pituitary incidentalomas was organized between March 1999 and May 2000 under the auspices of the study group of the hypothalamic and pituitary diseases, which belongs to the Ministry of Health, Labor and Welfare in Japan.

A pituitary incidentaloma was defined as a pituitary mass discovered incidentally on CT or MRI of the brain carried out for evaluation of an unrelated disease and where the patient did not complain of symptoms associated with a sellar mass (visual disturbance, symptoms of hypopituitarism, or anterior pituitary hormone excess). Headache was not considered as a symptom associated with a sellar mass in this study.

Patients with pituitary incidentalomas from 1996 to 2000 were studied.

The first questionnaire was sent to 151 institutes identified as specializing in pituitary diseases. The second questionnaire was sent to 71 institutes which had responded to the first survey.

Basically, baseline assessment included the following: clinical review, serum levels of growth hormone (GH), prolactin (PRL), thyrotropin (TSH), free thyroxine (fT4), follicle-stimulating hormone (FSH), luteinizing hormone $(\mathrm{LH})$, testosterone in men, adrenocorticotropin $(\mathrm{ACTH})$ and cortisol, visual acuity and visual field testing by Goldman perimetry and MRI of the pituitary. Patients who had evidence of hormone 
hypersecretion, except mild hyperprolactinemia $<100 \mathrm{ng} / \mathrm{dl}$, and/or visual impairment related to the pituitary mass were excluded.

Follow-up assessment was generally performed 3-6 months after baseline. Follow-up included clinical review, repeated hormone checks and visual field tests if there was any change in clinical status, and repeated MRI.

\section{Results}

Five hundred and six patients with incidentally found pituitary masses were included in this study. Of 506 patients, 258 underwent surgery (102 male and 146 female; mean age 53.9 years (range 17-78 years)) while 248 patients were followed (102 male and 146 female; mean age 48.7 years (range 10-82 years)). The 248 patients were followed for 6-173 months (mean 26.9 months at the time of survey).

All patients had no evidence of hormone hypersecretion or hyposecretion. Serum hormone levels of $\mathrm{GH}$, TSH, fT4, FSH, LH, ACTH and cortisol were within normal levels and PRL levels were $<100 \mathrm{ng} / \mathrm{dl}$. Patients with visual impairment due to the pituitary mass were excluded.

The reasons for head CT and/or MRI are shown in Table 1 . The most common reason was headache (190 patients, $37.5 \%$ ), followed by brain checkup (13.2\%), vertigo/tinnitus (11.5\%) and examination for other diseases $(13.0 \%)$ including cancer metastases, head injury, cerebral infarction and other cerebrovascular disease. Other symptoms included loss of consciousness, paresthesia and syncope.

The average size of the tumor was $26.5 \mathrm{~mm}$ in diameter. The reasons for surgical intervention of the 258 patients were: suprasellar extension of tumor (124 patients, 48.1\%); large macroadenoma (32 patients, $12.4 \%$ ); and patient's request (28 patients, $10.9 \%$ ). Transsphenoidal surgery was performed in 253 patients, and transcranial surgery was performed in five. Histological diagnosis of the tumors showed that $209(81.0 \%)$ were non-functioning pituitary adenomas and $41(15.9 \%)$ were Rathke's cyst (Table 2$)$.

In total, 248 patients were observed over 6 months to 14.5 years, an average period of 26.9 months.

Table 1 The reasons which led to MRI and/or CT.

\begin{tabular}{lccc}
\hline & $\begin{array}{c}\text { Surgical } \\
\text { group } \\
(n=258)\end{array}$ & $\begin{array}{c}\text { Non-surgical } \\
\text { group } \\
(n=248)\end{array}$ & $\begin{array}{c}\text { Total } \\
(n=506)\end{array}$ \\
\hline Headache & $102(39.5 \%)$ & $88(35.5 \%)$ & $190(37.5 \%)$ \\
Brain checkup & $41(15.9 \%)$ & $26(10.5 \%)$ & $67(13.2 \%)$ \\
Vertigo/tinnitus & $29(11.2 \%)$ & $24(9.7 \%)$ & $58(11.5 \%)$ \\
Head injury & $23(8.9 \%)$ & $12(4.8 \%)$ & $35(6.9 \%)$ \\
Other brain disease & $20(7.8 \%)$ & $46(18.5 \%)$ & $66(13.0 \%)$ \\
Other symptoms & $40(15.5 \%)$ & $52(21.0 \%)$ & $92(18.2 \%)$ \\
Unknown & 3 & 0 & 3
\end{tabular}

The average initial tumor size was $13.2 \mathrm{~mm}$ in diameter. The estimated diagnoses in non-surgical group patients were 115 non-functioning pituitary adenomas (46.4\%), 98 Rathke's cysts (39.5\%), ten other cysts $(4.0 \%)$ and 25 others $(10.0 \%)$. Of 242 patients followed up by MRI, the size of tumor has shown no change in $180(74.4 \%)$, increased in $30(12.4 \%)$ and decreased in $29(12.0 \%)$. The changes of tumor size in relation to other characteristics are shown in Table 3. The average ages of the patients with unchanged tumors, increased tumors and decreased tumors were 48.9, 54.7 and 42.1 years respectively. The mean initial diameters of increased tumors and decreased tumors were 13.9 and $13.7 \mathrm{~mm}$ respectively. The characteristics of the increased tumors are shown in Table 4. Of the increased tumor, ten were $<10 \mathrm{~mm}$ (micro) in size and 20 were $>10 \mathrm{~mm}$ (macro). The estimated diagnoses of the increased tumors consisted of 23 non-functioning pituitary adenomas and five Rathke's cysts and two others. The tumor increase averaged 45.5 months of the follow-up period (range 2-173 months). The decreased tumors consisted of 11 nonfunctioning adenomas, 15 Rathke's cysts and three others. The tumor decrease averaged 34.7 months of the follow-up period (range 5-98 months).

Of 115 estimated non-functioning adenomas, 23 $(20.0 \%)$ increased during a mean follow-up period of 50.7 months (range 10-173 months). On the other hand, of 94 estimated Rathke's cysts, five (5.3\%) increased during a mean follow-up period of 38.9 months (range 6-93 months).

During the follow-up period, ten patients underwent transsphenoidal surgery. Of these ten patients, six required surgery because of tumor enlargement, while four patients requested surgery in spite of the fact that tumor size had not changed. None of the six patients with tumor enlargement had shown visual disturbance or visual field defect, except one patient with pituitary apoplexy. Histopathology of the ten tumors revealed six non-functioning pituitary and four Rathke's cleft cysts.

Pituitary apoplexy occurred in one patient of 248 cases $(0.4 \%)$ during a mean follow-up of 26.9 months.

Table 2 Histological diagnosis (surgical group) and estimated diagnosis (non-surgical group) of pituitary incidentalomas.

\begin{tabular}{lcc}
\hline & $\begin{array}{c}\text { Surgical group } \\
(n=258)\end{array}$ & $\begin{array}{c}\text { Non-surgical group } \\
(n=248)\end{array}$ \\
\hline $\begin{array}{l}\text { Non-functioning } \\
\text { pituitary adenoma }\end{array}$ & $209(81.0 \%)$ & $115(46.4 \%)$ \\
Rathke's cyst & $41(15.9 \%)$ & $98(39.5 \%)$ \\
Arachnoid cyst & $5(1.9 \%)$ & $2(0.8 \%)$ \\
Other cyst & 0 & $8(3.2 \%)$ \\
Craniopharyngioma & $3(1.2 \%)$ & 0 \\
Physiological & 0 & $6(2.4 \%)$ \\
$\quad$ hypertrophy & 0 & $1(0.4 \%)$ \\
Hypophysitis & 0 & 18 \\
Others & & \\
\hline
\end{tabular}


Table 3 Change of tumor size in relation to general characteristics.

\begin{tabular}{|c|c|c|c|}
\hline & Decrease & Increase & Unchanged \\
\hline Number of patients & $29(12.0 \%)$ & $30(12.4 \%)$ & $180(74.4 \%)$ \\
\hline $\mathrm{M}: \mathrm{F}$ & $16: 13$ & $16: 14$ & $70: 110$ \\
\hline Mean age (years) & 42.1 & 54.7 & 48.9 \\
\hline Microadenoma & 7 & 10 & 57 \\
\hline Macroadenoma & 22 & 20 & 123 \\
\hline Average time to change & 31.3 months (2-78 months) & 45.5 months (6-173 months) & - \\
\hline Non-functioning adenoma $(n=115)^{\star}$ & $11(9.6 \%)$ & $23(20.0 \%)$ & $83(72.2 \%)$ \\
\hline Rathke's cyst $(n=94) \star \star$ & $15(15.9 \%)$ & $5(5.3 \%)$ & $72(76.5 \%)$ \\
\hline Cyst $(n=10)$ & 0 & 1 & 9 \\
\hline Others $(n=20)$ & 3 & 1 & 16 \\
\hline
\end{tabular}

* Included a patient whose tumor increased then decreased in size.

** Included two patients whose tumors increased and decreased in size.

\section{Discussion}

According to the literature, the incidence of incidentally found pituitary tumors (microadenomas) at the time of autopsy is $3-27 \%(1-3)$. MRI has been used as a routine diagnostic study not only in ordinary clinics but also in the study of the detection of asymptomatic brain disease (brain checkup). Clinically, asymptomatic pituitary incidentalomas are likely to be found more frequently than previously reported. The previous follow-up studies were limited, and the present study is the largest series to the best of our knowledge.

Of 506 patients with pituitary incidentalomas, about half underwent surgery and the other half were followed. During the follow-up period, the tumor size did not change in $74.7 \%$ of patients, increased in 33 $(13.3 \%)$ and decreased in $29(12.0 \%)$. The mean age

Table 4 Characteristics of patients with pituitary incidentalomas which increased during follow-up.

\begin{tabular}{|c|c|c|c|c|c|c|c|}
\hline \multicolumn{2}{|c|}{ Patient } & \multirow{2}{*}{$\begin{array}{l}\text { Reason } \\
\text { for MRI }\end{array}$} & \multirow{2}{*}{$\begin{array}{l}\text { Estimated } \\
\text { diagnosis }\end{array}$} & \multirow{2}{*}{$\begin{array}{l}\text { Initial tumor } \\
\text { size }(\mathrm{mm})\end{array}$} & \multirow{2}{*}{$\begin{array}{c}\text { Time increased } \\
\text { (months) }\end{array}$} & \multirow{2}{*}{$\begin{array}{c}\text { Tumor } \\
\text { size }(\mathrm{mm})\end{array}$} & \multirow[b]{2}{*}{ Comment } \\
\hline No. & Age/sex & & & & & & \\
\hline 1 & $49 / \mathrm{M}$ & Head injury & NF & 16 & 32 & 22 & - \\
\hline 2 & $64 / F$ & CVD & NF & 15 & 25 & 23 & - \\
\hline 3 & $30 / \mathrm{M}$ & Headache & Rathke & 12 & 6 & 14 & TSS \\
\hline 4 & $20 / \mathrm{M}$ & Head injury & Rathke & 12 & 14 & 15 & TSS \\
\hline 5 & $53 / F$ & galactorrhea & Rathke & 5 & 84 & 15 & - \\
\hline 6 & $30 / F$ & CVD & NF & 5 & 124 & 7 & - \\
\hline 7 & $55 / F$ & Vertigo & NF & 10 & 147 & 12 & - \\
\hline 8 & $66 / \mathrm{M}$ & Headache & NF & 5 & 18 & 7 & TSS \\
\hline 9 & $54 / F$ & Vertigo & NF & 1.7 & 19 & 2 & - \\
\hline 10 & $71 / \mathrm{F}$ & Headache & NF & 14 & 61 & 15 & - \\
\hline 11 & $71 / F$ & Vertigo & NF & 1.5 & 173 & 3 & - \\
\hline 12 & $67 / \mathrm{M}$ & Spinal tumor & NF & 18 & 32 & 22 & - \\
\hline 13 & $58 / F$ & Headache & NF & 7 & 69 & 18 & - \\
\hline 14 & $64 / \mathrm{M}$ & Headache & NF & 15 & 52 & 22 & - \\
\hline 15 & $59 / \mathrm{M}$ & Unknown & NF & 6 & 38 & 7 & - \\
\hline 16 & $46 / \mathrm{M}$ & Schizophrenia & NF & 20 & 16 & 24 & - \\
\hline 17 & $60 / F$ & Parkinson's & NF & 12 & 20 & 14 & - \\
\hline 18 & $45 / \mathrm{M}$ & Headache & NF & 20 & 55 & 25 & - \\
\hline 19 & $67 / F$ & Vertigo & Cyst & 7 & 16 & 8 & - \\
\hline 20 & $25 / F$ & Depression & Unknown & 10 & 9 & 13 & - \\
\hline 21 & $61 / F$ & Unknown & NF & 7 & 65 & 15 & - \\
\hline 22 & $72 / \mathrm{M}$ & Vertigo & NF & 30 & 69 & 40 & - \\
\hline 23 & $55 / F$ & Headache & NF & 20 & 33 & 25 & - \\
\hline 24 & $65 / \mathrm{M}$ & Headache & NF & 25 & 22 & $30 *$ & TSS \\
\hline 25 & $44 / \mathrm{M}$ & Headache & Rathke & 11 & 57 & 15 & - \\
\hline 26 & $62 / \mathrm{M}$ & Headache & NF & 30 & 26 & 32 & TSS \\
\hline 27 & $57 / F$ & Brain check & Rathke & 11 & 17 & 13 & - \\
\hline 28 & $76 / \mathrm{M}$ & Headache & NF & 25 & 30 & 30 & - \\
\hline 29 & $53 / \mathrm{M}$ & Brain check & NF & 13 & 10 & 14 & - \\
\hline 30 & $51 / \mathrm{M}$ & CVD & NF & 30 & 43 & 31 & TSS \\
\hline
\end{tabular}

CVD, cerebro vascular disease; NF, non-functioning pituitary adenoma; TSS, transsphenoidal surgery.

${ }^{*}$ Case 24 was operated due to pituitary apoplexy. 
of the patients with increased tumors was older than that of unchanged/decreased tumors (54.7 vs 42.1/48.9 years). There was no relationship between tumor size and enlargement. The MRI findings of increasing tumors were solid masses, which were estimated to be non-functioning pituitary adenomas. On the other hand, those of decreasing tumors tended to be cystic, which were supposed to be Rathke's cysts. This study suggests that a solid mass estimated to be an adenoma on MRI should be followed more carefully. The period to tumor enlargement was a mean 45.5 months after initial diagnosis up to 14 years. From these observations, patients with pituitary incidentaloma should be followed by MRI at least over 4 years.

Donovan \& Corenblum (8) followed up 31 incidentalomas for a mean of 6.4 years, of which five patients had an increase in tumor size, and only two patients had complications. They emphasized that only patients with incidentalomas $>10 \mathrm{~mm}$ in diameter develop tumor enlargement or complications. However, from our observations, conservative management can be indicated, even for macroadenomas. Pituitary apoplexy occurred in one patient of 248 cases $(0.4 \%)$ during a mean follow-up of 26.9 months in the present study. This results in an incidence of pituitary apoplexy from a pituitary incidentaloma of approximately $0.2 \%$ per year. Patients should be carefully informed of the possibility of pituitary apoplexy, especially the larger the tumor size. Any sudden change in the physical or ophthalmological findings should be interpreted as a possible sign of pituitary apoplexy, and emergency transsphenoidal surgery is indicated.

\section{Diagnosis}

When following pituitary incidentalomas without performing surgery, accurate diagnosis without histological confirmation is always a problem. To accurately diagnose pituitary tumors, dynamic MRI is the most helpful method for making the differential diagnosis of various intrasellar lesions. As described in the literature, when pituitary tumors arise, the normal pituitary gland becomes enhanced and the tumor becomes enhanced later. A combination of the T1- and T2-weighted MRI findings with the dynamic MRI findings enables accurate diagnosis of pituitary tumors. It is noteworthy that of 115 estimated non-functioning adenomas, $20 \%$ of tumors showed enlargement during a mean follow-up period of 4 years, while of 98 estimated Rathke's cysts, only $5.3 \%$ showed enlargement. The diagnosis on MRI is essential and useful for prognosis in pituitary incidentalomas. Therefore, we recommend that the first evaluation on MRI should be performed by a pituitary radiologist or neurosurgeon specializing in the diagnosis of pituitary lesions.

It is clear that routine hormonal screening should be performed to detect hypopituitarism. This evaluation should consist of assessment of both baseline anterior pituitary hormones (GH, PRL, TSH, ACTH, LH and FSH) and target hormones (fT4, testosterone or estradiol and cortisol). Stimulation tests using corticotropin-releasing hormone, GH-releasing hormone, TSH-releasing hormone and gonadotropin-releasing hormone (luteinizing hormone-releasing hormone) may be required to detect hypopituitarism.

For patients with a hormonally silent pituitary macroadenoma and no signs of visual field defects, optimal management also is not clear. Reinecke et al. (5) observed seven patients with large pituitary incidentaloma, and one patient had tumor enlargement (from 22 to $25 \mathrm{~mm}$ in diameter). Donovan et al. (8) observed 16 patients with macroadenomas for approximately 6 years. Two patients with macroadenoma had complications: apoplexy and visual field change. In our present study, the follow-up period was 6 months to 14 years (mean 26.9 months). In non-functioning adenomas surgically treated, tumor regrowth after 5-15 years of follow-up is reported in a significant percentage of patients $(15-40 \%)(12,13)$. The mean follow-up period of this study is insufficient to conclude that surgery is not necessary in all pituitary mass lesions. Further follow-up is required to clarify the natural history of pituitary incidentalomas.

\section{Therapeutic strategy}

If a pituitary incidentaloma is found, therapeutic strategies have to be explained to the patient and treatment must be selected with sufficient informed consent. In our series of pituitary incidentalomas (macroadenomas), $75 \%$ of patients did not show increase in tumor size during follow-up. It is noteworthy that of 115 estimated non-functioning adenomas, $20 \%$ showed tumor enlargement, while of 98 estimated Rathke's cysts, only $8.3 \%$ showed tumor enlargement. The first evaluation on MRI should be performed by a pituitary radiologist or neurosurgeon in order to distinguish pituitary adenomas from other mass lesions.

From results of the present study, we propose the following therapeutic strategy: (i) transsphenoidal surgery should be recommended for a solid mass which is attached to the optic chiasma as seen on MRI, especially in young patients, and (ii) other patients should be followed up by MRI every 6 months for the first 2 years, then yearly. Surgical treatment is unnecessary unless there is a change in the findings in these studies.

\section{Acknowledgements}

This work was supported by Grant in Aid from the Ministry of Health, Labor and Welfare, Japan. This work was carried out on behalf of the Study Group on the Hypothalamic and Pituitary Diseases of the Ministry of Health, Labor and Welfare in Japan. The other doctors and participating centers of the Study 
Group with more than three patients were: K Chihara and Y Okimura, Third Department of Internal Medicine, University of Kobe; H Nishioka, Department of Neurosurgery, Tokyo Medical School; M Kamio, Department of Neurosurgery, Jikei Medical School; K Mase, Department of Neurosurgery, Nagoya City University; K Nikawara, Department of Internal Medicine, Hirosaki University; S Izumimoto, Department of Neurosurgery, Osaka University; T Nishi, Department of Neurosurgery, Kumamoto University; N Tamaki, Department of Neurosurgery, Kobe University; M Kitano, Department of Neurosurgery, Kinki University; O Okuda, Department of Neurosurgery, Juntendo University; T Tamura and K Morii, Department of Neurosurgery, Niigata University; S Suzuki, Department of Neurosurgery, Yokohama City University; E Takeuchi, Department of Neurosurgery, Osaka Medical College; $\mathrm{T}$ Kawamata, Department of Neurosurgery, Tokyo Women's Medical College; T Abe, Department of Neurosurgery, Showa University; K Kuramoto, Department of Neurosurgery, Kurume University; K Kojima Department of Internal Medicine, Ohara General Hospital; T Yokoyama, Department of Neurosurgery, Kagoshima University; Y Ushikubo, Department of Neurosurgery, Toho University School of Medicine; A Tamura, Department of Neurosurgery, Teikyo University. There were other doctors from 21 institutes.

\section{References}

1 Molitch ME \& Russell EJ. The pituitary incidentaloma. Annals of Internal Medicine 1990112 925-931.

2 Molitch ME. Evaluation and treatment of the patient with a pituitary incidentaloma. Journal of Clinical Endocrinology and Metabolism $1995 \mathbf{8 0} 3-6$.
3 Soule SG \& Jacobs HS. The evaluation and management of subclinical pituitary disease. Postgraduate Medical Journal 199672 258-262.

4 Chacko AG \& Chandy MJ. Incidental pituitary macroadenomas. British Journal of Neurosurgery 19926 233-236.

5 Reinecke M, Allelio B, Saeger W, Menzel J \& Winkelman W. The 'incidentaloma' of the pituitary gland. Is neurosurgery required? Journal of the American Medical Association $1990 \mathbf{2 6 3}$ $2772-2776$.

6 Castello RT. Subclinical adenoma of the pituitary gland. American Journal of Pathology 193612 205-216.

7 Teramoto A, Hirakawa K, Sanno N \& Osamura RY. Incidental pituitary lesions in 1000 unselected autopsy specimens. Radiology $1994193161-164$.

8 Donovan MD \& Corenblum B. The natural history of the pituitary incidentaloma. Archives of Internal Medicine 1995155 $181-183$.

9 Parent AD, Bebin J \& Smith RR. Incidental pituitary adenomas. Journal of Neurosurgery $198154228-231$.

10 Hall WA, Luciano MG, Doppman JL, Patronas NJ \& Oldfield EH. Pituitary magnetic resonance imaging in normal human volunteers: occult adenomas in the general population. Annals of Internal Medicine $1994 \mathbf{1 2 0} 817-820$.

11 Feldkamp J, Santen R, Harms E, Aulich A, Modder U \& Schebaum WA. Incidentally discovered pituitary lesions: high frequency of macroadenomas and hormone-secreting adenomas - results of a prospective study. Clinical Endocrinology 199951 109-113.

12 Sassolas G, Trouillas J, Treluyer C \& Perrin G. Management of nonfunctioning pituitary adenomas. Acta Endocrinologica 1993 129 (Suppl 1) 21-26.

13 Turner HE, Stratton IM, Byrne JV, Adams CB \& Wass JA. Audit of selected patients with nonfunctioning pituitary adenomas treated without irradiation - a follow-up study. Clinical Endocrinology $199951281-284$.

Received 12 March 2003

Accepted 2 May 2003 